\title{
Isolated costal cartilage fractures: the radiographically overlooked injuries
}

\author{
S.-M. Yuan \\ $1^{\text {st }}$ Hospital of Putian, Teaching Hospital, Fujian Medical University, Putian, Fujian Province, China
}

[Received: 22 March 2016; Accepted: 7 May 2016]

\begin{abstract}
Isolated costal cartilage fractures are benign and rare. A 65-year-old man had a sustained chest pain after a fist punch in the past month. A 3-dimensional computed tomography revealed left $7^{\text {th }}$ and $8^{\text {th }}$ costal cartilage fractures with fracture dislocations. As he refused an open fracture reduction, he was advised to have a rest with subsequent follow-up. Ultrasound screening is recommended in patients with sustained posttraumatic chest pains in order to rule out possible costal cartilage fractures. The therapeutic regimen generally depends on the location and severity of the fracture. (Folia Morphol 2017; 76, 1: 139-142)
\end{abstract}

Key words: costal cartilage fracture, diagnostic imaging, thoracic injuries

\section{INTRODUCTION}

Isolated costal cartilage fractures are benign and rare. As cartilage is invisible on X-ray films, costal cartilage fractures are often unnoticeable on plain radiographs unless the costal cartilage is severely calcified [11]. As premised by Malghem et al. [6], in the flail chest fractures, the affected chondrocostal or chondrosternal junctions cannot be identified by radiographic examinations, either. Therefore, costal cartilage fractures and damages are often underestimated [7]. Due to the fact that isolated costal cartilage fractures are often overlooked in conventional radiographic imaging, the diagnosis is sometimes challenging and a definite diagnosis is not established until the causes of an unexplained posttraumatic chronic chest pain are sorted out. In this article, a case of isolated costal cartilage fractures is described.

\section{CASE REPORT}

A 65-year-old man had a sustained chest pain after a fist punch in the past month. Repeated chest radiographs in a local hospital did not reveal any abnormalities. Thus, he was referred to this hospital for further evaluations. Physical examination revealed a knoblike protuberance with an indistinct boundary measuring about $5 \times 5 \mathrm{~cm}$ in the left costal arch. There was a defined soft tissue swelling with apparent tenderness. A 3-dimensional computed tomography (CT) illustrated left $7^{\text {th }}$ and $8^{\text {th }}$ costal cartilage fractures with fracture dislocations (Fig. 1). As he refused an open fractures reduction, he was advised to have a rest with subsequent follow-up.

\section{DISCUSSION}

There have been no explicit standards for classifications of causes of injuries. The causative factors responsible for isolated costal cartilage fractures could be aligned in two ways, either based on patient population or based on nature of injury (Table 1) [4]. Drivers and occupants were the most commonly affected population and traffic accident injury was the most common cause [4], whereas fist injury only accounted for $6.3 \%$ [4]. In general, isolated costal cartilage fractures often occur in the lower ribs and

Address for correspondence: Dr S.-M. Yuan, $1^{\text {st }}$ Hospital of Putian, Teaching Hospital, Fujian Medical University, Putian, Fujian Province, People's Republic of China, tel: 86594 6923117, e-mail: shi_min_yuan@yahoo.com; shiminyuan@126.com 

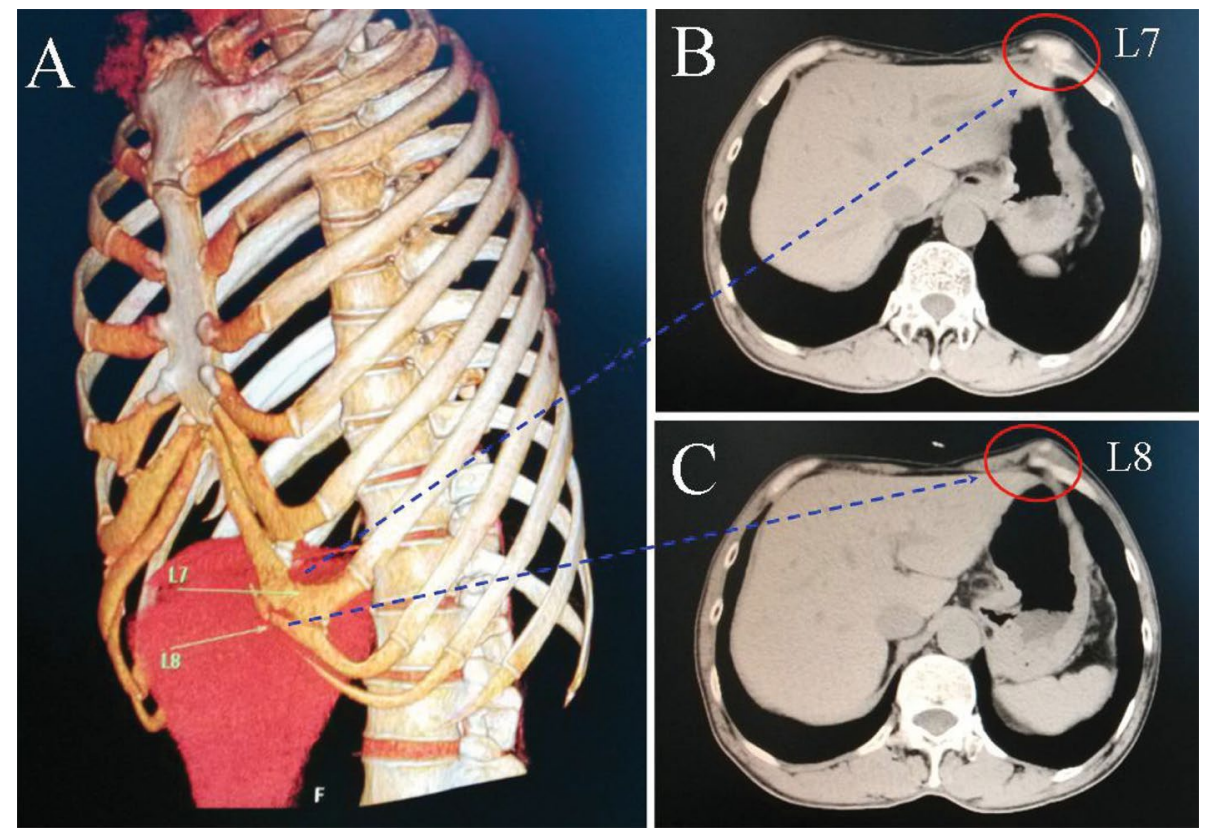

Figure 1. Computed tomography showing left $7^{\text {th }}$ and $8^{\text {th }}$ costal cartilage fractures with fracture dislocations, on (A) 3-dimensional reconstruction view; and (B) and (C) on axial views; L7 - left $7^{\text {th }}$ costal cartilage; L8 - left $8^{\text {th }}$ costal cartilage.

Table 1. The causative factors of isolated costal cartilage fractures [4]

\begin{tabular}{llc}
\hline $\begin{array}{l}\text { Causative factors } \\
\text { of injury }\end{array}$ & $\begin{array}{l}\text { Patient } \\
\text { population }\end{array}$ & $\mathbf{N}(\%)$ \\
\hline Traffic accident injury & Passenger & $41(64.1 \%)$ \\
& Driver and occupant & $24(58.5 \%)$ \\
& Driver-seat & $10(41.7 \%)$ \\
& Front-seat & $9(37.5 \%)$ \\
& Back-seat & $5(20.8 \%)$ \\
& Pedestrian & $7(17.1 \%)$ \\
Bicyclist & $4(9.8 \%)$ \\
Mechanical injury & Motorcyclist & $6(14.6 \%)$ \\
& Worker or so & $5(7.8 \%)$ \\
Call down & Cultivator & $3(60 \%)$ \\
Sport injury & Victim of heavy & $2(40 \%)$ \\
object impact & \\
Roll down & Athlete & $5(7.8 \%)$ \\
& Rugby player & $1(50 \%)$ \\
& Boxer/brawler & $4(50 \%)$ \\
& Others & $13(20.3 \%)$ \\
& & $7(53.8 \%)$ \\
& & $0(46.2 \%)$ \\
& & $0(0 \%)$ \\
\hline
\end{tabular}

are typically caused by the direct impact from a blunt chest trauma [5].

The major complaints of the patients are chest pains, especially when he/she is breathing, turning round, forwarding shoulders, or in whole-body movements. It can be mistaken for symptoms of a heart attack. The symptoms can be aggravated by compressing, long periods of sitting, sneezing, or blowing the nose [7].

Ultrasound is a preferred diagnostic method of costal cartilage fractures in most of the patients for its superior sensitivity [5]. CT and magnetic resonance imaging are also reliable diagnostic means for cartilage injuries [5]. The indications for CT or ultrasound examination are unexplained sustained posttraumatic chest pains, or a chronic painful lump of unknown origin [6]. Cartilage fractures are often located at the chondrocostal or chondrosternal junction for the first costal cartilages, while they occur at the mid-portion for other costal cartilages [6]. Subperiosteal haematoma was the most common finding associated with costal cartilage fractures (15.0\%), followed by sternal fracture $(9.7 \%)$ [4]. The first three costal cartilage fractures predispose to possible tracheal, bronchial and intrathoracic cardiovascular injuries [2]. 
Ultrasound is a convenient and precise diagnostic method, by which the sensor can be precisely placed on the painful area. In ultrasound, the cartilage is less echoic than the adjacent muscles and is well bounded by the visibility of an echogenic line [6]. An ultrasound imaging at the level of the palpable mass reveals a linear region of hyperechogenicity within the hypoechoic costal cartilage that is consistent with a costal cartilage fracture [8]. The fracture line can be visualised as a displaced or non-displaced discontinuity crack in the affected cartilage, which can be highlighted by the presence of air [1]. Griffith et al. [3] found, in a sonographic study of patients with suspected rib fracture, that $11 \%$ of fractures were located in the costal cartilage or at the chondrocostal junction, and none of the lesions were diagnosed by using a conventional radiograph.

$\mathrm{CT}$ images consistently revealed a focal discontinuity of the costal cartilage [6]. Malghem et al. [6] reported that CT demonstrated costal cartilage fractures with displacement in $33.3 \%(5 / 15)$, and adjacent soft tissue swelling in $26.7 \%(4 / 15)$ of the lesions. They also noted that $26.7 \%(4 / 15)$ of the costal cartilage fractures involved the chondrosternal or chondrocostal junction, with a good linear limpidity with a gas density seen in the cartilaginous cleft [6].

18F-fluorodeoxyglucose (FDG) positron emission tomography (PET)/CT, by means of FDG accumulation, is valuable for determining the costal lesion by confirming the fracture line, compensating the missed diagnosis by contrast-enhanced chest $\mathrm{CT}$ [10]. However, FDG PET/CT is not cost-effective in the diagnosis of costal and costal cartilage fractures [10]. Moreover, the costal injury is more apparent on fat-suppressed T2-weighted coronal magnetic resonance imaging with a high signal at the injury site [9].

Conservative treatment, including bed rest, fixation with a chest belt and analgesia regime, is preserved for patients with isolated non-displaced single costal cartilage fracture or fractures of the costal arch. Closed-chest drainage may be necessary in some of the patients. Costal cartilage fracture fixation is warranted in the patients associated with multiple costal or sternal fractures. Patients with a severe posttraumatic chest pain or a costal cartilage fracture with obvious displacement should undergo stump revision or binging and fixation with a heavy silk thread or steal wire, which, however, may reveal poor outcomes especially for those with parasternal dislocation or complete detachment [12]. The recent developed memory alloy rib embracing fixator for multiple rib fractures enables fixation of costal cartilage fracture possible by jointing sternum, costal cartilages and ribs by a specially designed long arm of the embracing fixator. It is especially indicated for the comminuted fracture of the costal cartilage. The attractive biocompatible properties of the nickeltitanium memory alloy material allow us to leave the embracing fixator in vivo without the need of removal after the operation [12]. Wang et al. [12] treated 14 patients with costal cartilage fracture with the memory alloy rib embracing fixator and achieved good results. Two of their patients requested the removal of the embracing fixator, whereupon the costal cartilage fractures healed perfectly and the fracture traces were hardly seen.

\section{CONCLUSIONS}

Isolated costal cartilage fracture is a rare and benign lesion. The diagnosis of isolated costal cartilage fracture is sometimes challenging as it is usually overlooked by conventional radiographic examinations. Ultrasound screening is recommended in patients with sustained posttraumatic chest pains due to its superior sensitivity in order to rule out costal cartilage fractures. The therapeutic regimen generally depends on the location and severity of the fracture.

\section{REFERENCES}

1. Bienvenot $P$, Phan $C$, Miquel $A$, et al. Les fractures du cartilage costal: un diagnostic souvent méconnu. J Traumatol Sport. 2011; 28(2): 107-109, doi: 10.1016/j. jts.2011.04.008.

2. Cameron $P$, Dziukas $L$, Hadj $A$, et al. Rib fractures in major trauma. Aust N Z J Surg. 1996; 66(8): 530-534, doi: 10.1111/j.1445-2197.1996.tb00803.x, indexed in Pubmed: 8712986.

3. Griffith JF, Rainer TH, Ching AS, et al. Sonography compared with radiography in revealing acute rib fracture. AJR Am J Roentgenol. 1999; 173(6): 1603-1609, doi: 10.2214/ ajr.173.6.10584808, indexed in Pubmed: 10584808.

4. Lee WS, Kim YH, Chee HK, et al. Ultrasonographic evaluation of costal cartilage fractures unnoticed by the conventional radiographic study and multidetector computed tomography. Eur J Trauma Emerg Surg. 2012; 38(1): 37-42, doi: 10.1007/s00068-011-0117-2, indexed in Pubmed: 26815671.

5. Lopez $\mathrm{V}, \mathrm{Ma}$ R, Li X, et al. Costal cartilage fractures and disruptions in a rugby football player. Clin J Sport Med. 2013; 23(3): 232-234, doi:10.1097/JSM.0b013e31825b55ed, indexed in Pubmed: 22627657. 
6. Malghem J, Vande Berg B, Lecouvet F, et al. Costal cartilage fractures as revealed on $C T$ and sonography. AJR Am J Roentgenol. 2001; 176(2): 429-432, doi: 10.2214/ ajr.176.2.1760429, indexed in Pubmed: 11159088.

7. Noreen K. Symptoms of damage to the costal cartilage. http://www.healthguideinfo.com/orthopedic/p67746/. Accessed on March, 22: 2016.

8. Orth RC, Laor T. Isolated costal cartilage fracture: an unusual cause of an anterior chest mass in a toddler. Pediatr Radiol. 2009; 39(9): 985-987, doi:10.1007/s00247-0091276-8, indexed in Pubmed: 19415256.

9. Subhas N, Kline MJ, Moskal MJ, et al. MRI evaluation of costal cartilage injuries. AJR Am J Roentgenol. 2008;
191(1): 129-132, doi: 10.2214/AJR.07.3396, indexed in Pubmed: 18562735.

10. Tasdemir B, Unal K, Dostbil Z. 18-F FDG PET/CT diagnosed costal cartilage fracture which was missed by thorax $\mathrm{CT}$ : an incidental finding in a case. Int J Basic Clin Studies. 2014; 3: 83-86.

11. Torreggiani WC, Lyburn ID, Thornton F, et al. Fracture of the costal cartilage: computed tomography assists diagnosis. J HK Coll Radiol. 2001; 4: 274-276.

12. Wang YQ, Geng Y, Bai S, et al. Novel sternal-costal memory alloy embracing fixator for the treatment of traumatic costal cartilage fracture in 24 patients. Shaanxi Med J. 2013; 42: 1525-1526. 